\title{
PENERAPAN METODE FONIK UNTUK GAME EDUKASI PENYANDANG DISLEKSIA MENGGUNAKAN VISUAL NOVEL
}

\author{
Risma Shafriyani $^{1}$, Hasanuddin ${ }^{2}$, Febby Apri Wenando ${ }^{3}$ \\ ${ }^{123}$ Fakultas Ilmu Komputer Universitas Muhammadiyah Riau \\ 1email : rismashafriyani95@gmail.com \\ ²email : hasan@umri.ac.id \\ 3email : febby@umri.ac.id
}

\begin{abstract}
Multimedia that can help dyslexic children. Visual Novel is an interactive based game that displays stories in the form of static images, and is equipped with conversation boxes to convey narratives and sayings of each character, and sometimes each character has a sound effect so that every character in Visual Novel seems to be alive and able to speak. The method used in making this game is multimedia development life circle, and for the game itself, the phonics method will be used. As for the background of this writing, there is no Indonesian visual novel that has become a learning medium for children with dyslexia. And also visual novel is recommended to be used as a learning media, because it can help children enjoy the learning contained in it.
\end{abstract}

Key words : Dyslexia, Visual Novel, Phonetic Method

\section{PENDAHULUAN}

Perkembangan teknologi telah memberikan berbagai perubahan yang baik di berbagai bidang, termasuk dalam bidang pendidikan serta hiburan yang memiliki peran dalam peningkatan mutu pembelajaran kepada anak-anak. Salah satunya dalam dunia game, sering digunakan sebagai sarana hiburan bagi kalangan anak-anak hingga kalangan dewasa. Didalam perkembangan dunia game saat ini terutama pada game Android sudah semakin banyak dan bervariasi. Dari beberapa game yang berbasis Android terutama pada game yang bergenre edukasi yang menjadi media pembelajaran bagi anak yang menderita Disleksia. (Azizah, 2016)
Disleksia merupakan kesulitan belajar primer berkaitan dengan masalah bahasa tulisan seperti membaca, menulis, dan mengeja. (Madinatul Munawaroh, 2015). Disleksia tidak bisa disembuhkan, namun hanya bisa membaik. Penelitian di Negara maju menunjukkan bahwa deteksi disleksia sejak dini serta penanganan yang baik akan memberikan hasil yang baik juga. (Tammasse, 2017)

Meskipun sudah ada media
pembelajaran untuk anak yang
menyandang Disleksia, belum ada
multimedia pembelajaran interaktif
sebagai media pendukung proses
pembelajaran yang menekankan pada
aspek audio khususnya dalam kegiatan
belajar membaca bagi anak Disleksia
(Arifah, 2017)
(Arifah, 2017) 
Salah satu metode yang digunakan untuk menstimulasi penderita Disleksia, yaitu dengan Metode Fonik. Metode Fonik adalah suatu cara yang digunakan untuk mengajarkan anak dalam belajar membaca permulaan, dengan menekankan pada pengenalan kata melalui proses mendengarkan bunyi yang disintetiskan menjadi suku kata dan kata. (Ardyanti, 2015)

Alasan pemilihan Metode Fonik dalam penelitian ini adalah anak-anak disleksia yang lebih besar merasakan kesulitan membaca, sering merasa metode ini baik untuk diterapkan kepada anak disleksia. Kebanyakan terapis cenderung menggabungkan metode yang berbeda, tergantung tinggkat kesulitan anak disleksia yang berbeda dari metode yang berbeda pada tingkat yang sama berbeda. (Virdyna, 2015).

Perkembangan teknologi yang semakin pesat dan selalu berkembang baik, pada aspek kognitif maupun psikomotor sangat membantu dalam menemukan jawaban dan solusi atas permasalahan yang dihadapi. Salah satunya pada bidang pendidikan yaitu untuk mengatasi kesulitan belajar pada siswa, seperti disleksia. Metode Fonik yang dapat dilakukan untuk membantu anak Disleksia, metode tersebut dapat dikaji kembali dan dikemas menjadi media pembelajaran dalam bentuk game agar lebih menarik. (Sri Respati Andamari, 2017)

Didalam perkembangan dunia game saat ini terutama pada game Android sudah semakin banyak dan bervariasi. Dari beberapa game yang berbasis Android terutama pada game yang bergenre edukasi yang menjadi media pembelajaran bagi anak yang menderita disleksia. (Azizah, 2016) Belum adanya multimedia pembelajaran interaktif sebagai media pendukung proses pembelajaran yang menekankan pada aspek audio khususnya dalam kegiatan belajar membaca bagi anak Disleksia (Arifah, 2017)

Visual Novel merupakan game berbasis interaktif yang menampilkan cerita dalam bentuk gambar-gambar statis, dan dilengkapi dengan kotak percakapan untuk menyampaikan narasi dan ucapan setiap karakter, dan terkadang setiap karakter memiliki efek suara sehingga setiap karakter yang ada dalam Visual Novel seolah hidup dan dapat berbicara. Visual Novel juga di rekomendasikan agar digunakan sebagai konsep dari sebuah pembelajaran, karena dapat membantu siswa menikmati pembelajaran yang terdapat di dalamnya. Visual Novel game dapat membantu meningkatkan kualitas pembelajaran lebih lanjut. (Adrie Satrio, 2017) .

Game therapy adalah menggunakan media game untuk terapi. Dijelaskan oleh Mader, Natkin, dan Levieux (2002) bahwa game therapy merupakan salah satu bentuk terapi dimana game difungsikan menjadi sebuah pengaturan terhadap kondisi khusus atau pemberian perlakuan untuk meredakan penyakit dan gangguan dalam hal ini kondisi psikologis. Dalam kamus terapi memiliki lebih dari 200 enis terapi yang berbeda, salah satu di antaranya adalah game therapy. (Muhaeminah, Tahun, 2015)

\section{TINJAUAN PUSTAKA}

\section{Disleksia}

Disleksia merupakan salah satu bentuk kesulitan belajar spesifik yang tersering diantara kedua bentuk kesulitan belajar spesifik lainnya yaitu disgrafia dan diskalkulia. Disleksia yang berasal dari bahasa Greek secara harafiah mengandung makna kesulitan berbahasa. Disleksia terjadi pada individu dengan potensi kecerdasan normal, bahkan banyak diantara mereka yang mempunyai tingkat 
kecerdasan jauh di atas rata-rata. Itulah sebabnya maka disleksia disebut sebagai kesulitan belajar spesifik, karena kesulitan belajar yang dihadapinya hanya terjadi pada satu atau beberapa area akademis yang spesifik saja, diantaranya area membaca, menulis dan berhitung. Seringkali disleksia merujuk pada kondisi dimana kesulitan belajar yang nampak pada individu tersebut sulit dijelaskan karena demikian 'berlawanan' dengan potensi kecerdasan yang dimilikinya. Sebagian besar orang awam memahami disleksia sebagai kondisi dimana anak sulit belajar baca, malas menulis, jika menulis banyak huruf yang hilang, sulit menghitung, dan sebagainya, namun sejatinya disleksia sama sekali tidak sesederhana itu.

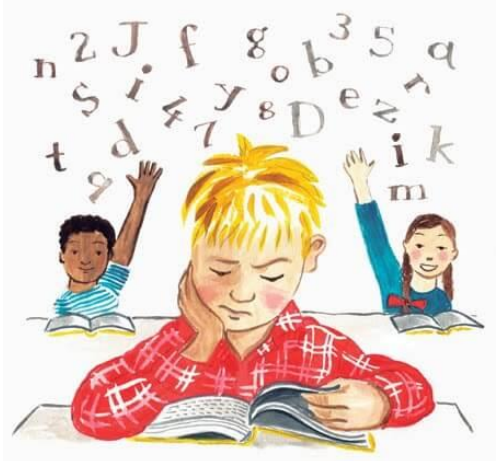

Gambar 1 Disleksia

Area belajar yang terlibat dalam kesulitan belajar spesifik meliputi area Proseding Seminar Nasional PGSD UPY dengan Tema Strategi Mengatasi Kesulitan Belajar ketika Murid Anda seorang Disleksia yang luas dan kompleks. Area pertama adalah area ketrampilan akademis, meliputi kemampuan membaca, menulis, mengeja, aritematika dan bahasa, baik bahasa lisan, bahasa tulisan maupun bahasa sosial. Area kedua adalah area executive function yang juga sangat penting dan sangat dibutuhkan dalam kehidupan sehari-hari, seperti halnya kemampuan untuk mengelola sesuatu, kemampuan mengendalikan impulsivitas, kemampuan bersosialisasi, persistensi atau ketekunan dalam menuntaskan suatu pekerjaaan, dan juga ketrampilan koordinasi motorik.

Hal lain yang membuat disleksia menjadi suatu kasus cukup kompleks adalah banyaknya penelitian yang melaporkan bahwa sekitar sepertiga kasus disleksia biasanya diikuti dengan gangguan perilaku lainnya, terutama Gangguan Pemusatan Perhatian dan Hiperaktivitas atau yang biasa dikenal Attention Deficit Hyperactivity Disorder (ADHD). Penelitian menunjukkan bahwa beberapa marka genetik yang berperan pada kejadian disleksia juga turut bertanggung jawab pada keadaan ADHD, itu sebabnya kondisi disleksia dan ADHD tidak jarang terjadi bersamaan.

Oleh karena itu, kasus disleksia tidak lah sesederhana sekedar kesulitan baca tulis dan hitung saja, apalagi gejala klinis disleksia pada satu individu bisa demikian berbeda dengan kasus disleksia pada individu disleksia lainnya. Dibutuhkan profesional yang amat mumpuni yang dapat mengenali dan memahami kasus disleksia secara komprehensif.

Di luar segala rupa 'kesulitannya' itu, anak disleksia juga mempunyai banyak area minat dan bakat yang luar biasa, misalnya mempunyai kemampuan imaginatif yang luar biasa, kemampuan bermain konstruktif yang di luar usianya, kemampuan bermusik atau berolahraga yang sangat terampil, atau anak yang jago sekali bermain strategi pada berbagai permainan yang membutuhkan ketrampilan problem solving tingkat tinggi. (Dewi, 2015)

\section{Metode Fonik}

Metode fonik adalah sebuah model pembelajaran bahasa yang ditujukan untuk anak usia dini dan dikembangkan dengan 
mengoptimalkan seluruh ketrampilan berbahasa, menyimak, berbicara, menulis dan membaca1. Metode ini adalah metode membaca dengan bunyi huruf (phone), tidak dieja seperti zaman saya belajar membaca dulu. Misalnya mengenalkan "a[ei]" for apple[eipel]", "b[beh] for boy[boi] dst. Sehingga dengan fonik anak tidak hanya bisa membaca tapi juga bisa berbahasa Inggris dengan baik dan benar (Virdyna, 2015)

Beberapa kelebihan dari metode ini adalah: (1). Dapat diajarkan dengan struktur bahasa yang disesuaikan dengan kaidah linguistik dan perkembangan bahasa anak. (2). Dapat dilakukan di sekolah dan di rumah. (3). Dilaksanakan sesuai dengan kerja otak anak, tidak memaksa, bermakna dan kontekstual. (4). Anak paham bahasa Indonesia bukan hanya sekadar bisa membaca.(5). Mengajarkan cara menulis yang proporsional dengan cara yang menyenangkan.

\section{Game}

Menurut Sudarmilah, dkk. (2015), dalam Jurnalnya yang berjudul "Popular Game, Can Any Concept of Cognitive Preschoolers Be In It?" menerangkan bahwa game pada awalnya dibuat untuk tujuan kesenangan dan hiburan, tapi mereka baru-baru ini mengarahkannya pada hal-hal yang memberikan keuntungan lebih pada user, sehingga disebut dengan game serius. Game yang serius menggunakan pendidikan untuk memasukan sesuatu yang berguna melalui pengalaman dalam bermain game.

Menurut Handriyantini dalam Molina (2014), game edukasi adalah permainan yang dirancang atau dibuat untuk merangsang daya pikir termasuk meningkatkan konsentrasi dan memecahkan masalah. Molina, masih pada penelitian yang sama menambahkan bahwa, Edugame adalah sebuah permainan yang digunakan dalam proses pembelajaran dan dalam permainan tersebut mengandung unsur mendidik atau nilai-nilai pendidikan.

Menurut Lynceo Falavigna Braghirolli (2016), game mempunyai kontribusi untuk memotivasi dalam pembelajaran. Permainan dapat merangsang untuk belajar sesuatu yang baru dan dapat memberikan pengalaman yang menyenangkan bagi peserta didik karena terjalin interaksi antar pemain, selain itu dapat memberikan dasar bagi pencapaian macam-macam keterampilan untuk memecahkan masalah. Namun jika pelaksanaan permainan tidak dipantau oleh guru akan terjadi kesalahan dalam teknis pelaksanaan dikarenakan asyik atau tidak paham aturan. Selain itu permainan yang kurang menantang atau susah akan mengakibatkan peserta didik cepat bosan.

\section{Visual Novel}

Visual Novel adalah game yang menggunakan gaya penceritaan seperti halnya sebuah novel, divisualisasi dengan gambar berupa tokoh dari novel tersebut, gambar kejadian-kejadian yang patut divisikan, dan gambar pemandangan dengan background dimana karakterkarakter itu sedang berada.

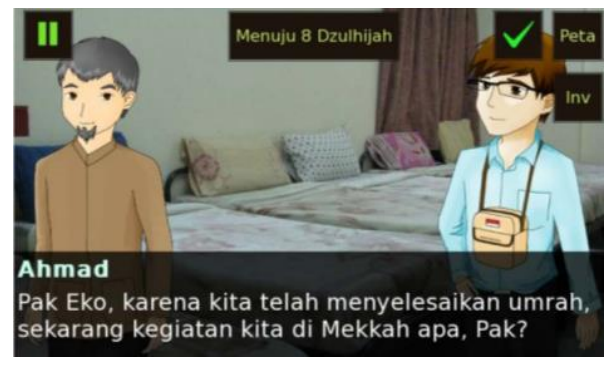

Gambar 2 Visual Novel

\section{Rule Based Reasoning (RBR)}

Pada pembuatan game ini, akan digunakan software yaitu Ren'Py. Menurut situs http://www.renpy.org/, Ren'Py adalah sebuah framework permainan di dalam bahasa pemrograman Python yang memiliki berbagai macam 
fitur lengkap di dalam pembuatan aplikasi lain seperti pembelajaran interaktif.

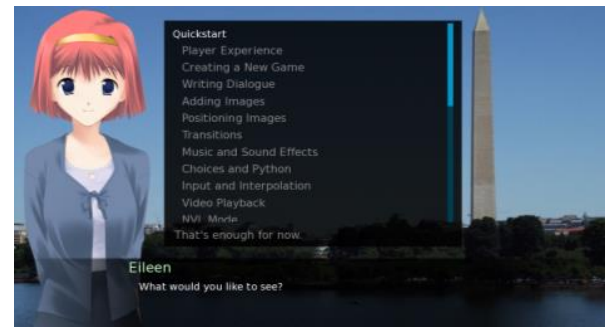

Gambar 3 Ren'Py

Ren'Py merupakan software sederhana yang membantu para sastrawan yang ingin membuat sebuah novel yang dikemas dengan gambar, suara, serta video, dengan menggunakan bahasa pemrograman Python sebagai syntax perintah utamanya. Alasan penggunaan Python sebagai bahasa pemrograman utamanya karena syntax-nya yang sangat mudah dipahami mendukung game simulasi yang kompleks. Dan di dalam renpy itu juga akan menggunakan 2 tool yaitu Ren'Py Android Packaging Tool (RAPT) dan Renpy Hotspot Tool.

\section{Gradle}

Gradle adalah suatu fitur build automation yang open source. Gradle didesain untuk membuat multi-project yang sedang berkembang menjadi project berskala besar. File Gradle terdiri dari file settings.gradle dan build.gradle. build.gradle berisi pengaturan global mengenai aplikasi pada Android Studio. Sedangkan settings.gradle berisi project mana saja yang akan dicompile di Android Studio tersebut.

\section{RAPT}

RAPT Adalah sebuah program, diunduh secara terpisah dari Ren'Py, yang menciptakan dan paket Android untuk tujuan pengujian atau pengurangan.

8. Python

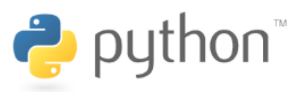

\section{Gambar 4 Python}

Ren'Py ditulis dalam bahasa pemrograman Python, dan termasuk dukungan untuk memasukkan Python ke dalam skrip Ren'Py. Dukungan python dapat digunakan untuk banyak hal, mulai dari mengatur bendera hingga membuat tampilan baru. Bab ini membahas caracara di mana skrip Ren'Py dapat secara langsung memanggil Python, melalui berbagai pernyataan Python.

\section{Ren'Py Hotspot Tool}

Membuat titik koordinat pada Visual Novel di Ren'Py bisa memakan waktu yang lama, maka dari itu untuk mempermudah dan mempersingkat waktu maka akan digunakan Ren'Py Hotspot Tool.

\section{Photoshop}

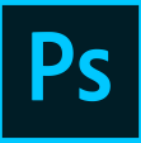

\section{Gambar 5 Photoshop}

Untuk pengeditan gambar, Adobe Photoshop, atau biasa disebut Photoshop, adalah perangkat lunak editor citra buatan Adobe Systems yang dikhususkan untuk pengeditan foto/gambar dan pembuatan efek. Perangkat lunak ini banyak digunakan oleh fotografer digital dan perusahaan iklan sehingga dianggap sebagai pemimpin pasar (market leader) untuk perangkat lunak pengolah gambar/foto, dan, bersama Adobe Acrobat, dianggap sebagai produk terbaik yang pernah diproduksi oleh Adobe Systems. Versi kedelapan aplikasi ini disebut dengan nama Photoshop CS (Creative Suite), versi sembilan disebut Adobe Photoshop CS2, versi sepuluh disebut Adobe Photoshop CS3 , versi kesebelas adalah Adobe Photoshop CS4, versi keduabelas adalah Adobe Photoshop CS5 , dan versi terbaru adalah Adobe Photoshop CC. 


\section{Android}

Android adalah sebuah sistem operasi yang perangkat mobile berbasis linux yang mencakup sistem operasi, middleware dan aplikasi. Android menyediakan platform terbuka lagi para pengembang untuk menciptakan aplikasi mereka. Awalnya, Google Inc. membeli Android Inc. yang merupakan pendatang baru yang membuat perangkat lunak untuk ponsel smartphone.

Kemudian untuk mengembangkan Android, dibentuklah Open Hanset Alliance, konsirsium dari 34 perusahaan peranti keras, perangkat lunak, dan telekomunikasi, termasuk Google, HTC, Intel, Motorola, Qualcomm, T-Mobile, dan Nvidia. Pada masa saat ini kebanyakan vendor-vendor smartphone sudah memproduksi smart phone berbasis Android, vendor-vendor itu antara lain HTC, Motorola, Samsung, LG, HKC, Huawei, Archos, Webstation Camangi, Dell, Nexus, SciPhone, WayteQ, Sony Ericsson, LG, Acer, Philips, T-Mobile, Nexian, IMO, Asus dan masih banyak lagi vendor smartphone diduni yang memproduksi Android. Hal ini karena Android itu adalah sistem operasi yang open source sehingga bebas didistribusikan dan dipakai oleh vendor manapun.

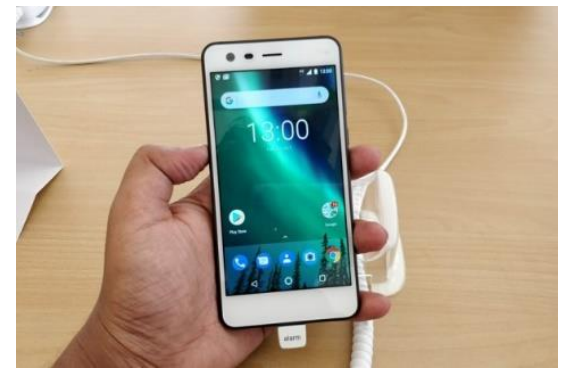

Gambar 6 Smartphone Android

Tidak hanya menjadi sistem operasi di smartphone, saat ini Android menjadi pesaing utama dari Apple pada sistem operasi Tablet PC. Pesatnya pertumbuhan Android selain faktor yang disebutkan diatas adalah karena Android itu sendiri adalah platform yang sangat lengkap baik itu Sistem Operasinya, Aplikasi dan Tool Pengembangan, Market aplikasi Android serta dukungan yang sangat tinggi dari komunitas Open Source di dunia, sehingga Android terus berkembang pesat baik dari segi teknologi maupun dari segi jumlah device yang ada didunia. (Safaat, 2015)

\section{MDLC}

Multimedia Development Life Cycle Penelitian ini memiliki tujuan mengembangkan sebuah media pembelajaran yang lebih menarik dan efisien menggunakan Augmented Reality dengan memanfaatkan fitur kamera Smartphone Android/iOS. dimana metode ini memiliki 6 tahapan, yaitu concept, design, material collecting, assembly, testing dan distribution.

\section{Sublime Text}

Sublime Text adalah sebuah teks editor yang sangat canggih untuk coding, markup dan lain-lain. Anda akan menyukai antarmuka pengguna yang sangat sederhana -mengingatkan dulu 4 tahun menggunakan centos-, fitur yang luar biasa serta kinerja yang tidak kalah luar biasa.

Pernah dulu Saya beberapa bulan menjadi programmer dengan bahasa Python, ternyata Sublime Text adalah sebuah syntax editor yang menggunakan Python API. Editor ini juga didukung oleh banyak plugin yang akan membuat Anda tutup mata dalam membuat baris program. Sublime Text dikembangkan oleh Jon Skinner, seorang programmer dari Australia.

\section{METODOLOGI PENELITIAN}

Dalam penelitian ini metode yang digunakan adalah Multimedia Development Life Cycle, dimana metode ini memiliki 6 tahapan, yaitu Perancangan Konsep, Desain, Pengumpulan Materi, 
Penyusunan dan Pembuatan, Pengujian dan Penyebarluasan.

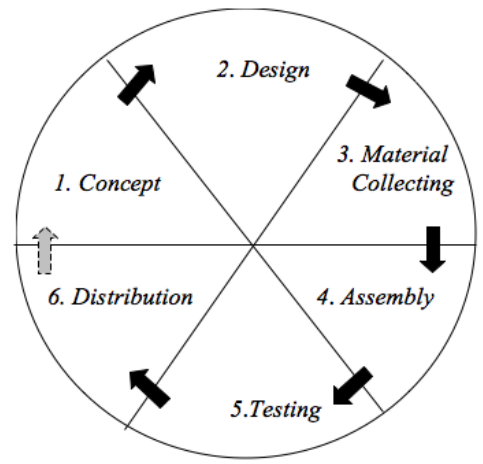

Gambar 7 MDLC

\section{HASIL DAN PEMBAHASAN}

\section{Perancangan Konsep}

Untuk penamaan game ini, game ini akan diberikan dengan judul fonika. Karena game ini menggunakan metode fonik didalamnya. Pemilihan audiens dipilih dalam rentan usia 5-11 tahun karena itu adalah usia anak sudah mengenal gadget. Untuk durasi permainannya sendiri akan memakan waktu sekitar 5 menit dan untuk penggunaan image nantinya akan menggunakan image dengan format jpg dan png. Dan yang terakhir audio akan menggunakan suara yang direkam kedalam format mp3. Untuk lebih jelasnya akan dijelaskan pada deskripsi konsep berikut :

\section{Tabel 1 Deskripsi Konsep}

\begin{tabular}{|l|l|}
\hline Judul & Fonika \\
\hline Audiens & Umur 5-11 tahun \\
\hline Durasi & 5 Menit \\
\hline Image & $\begin{array}{l}\text { Menggunakan gambar } \\
\text { dengan format jpg dan png }\end{array}$ \\
\hline Audio & $\begin{array}{l}\text { Menggunakan file rekaman } \\
\text { mp3 }\end{array}$ \\
\hline
\end{tabular}

\section{Desain}

1. Storyline

Storyline pada game ini akan memeiliki 3 buah scene dengan 2 buah latar tempat yaitu di rumah dan dipasar. Alur dari cerita ini adalah menceritakan tentang seorang ibu yang mengajadi anaknya mengenal huruf-huruf kemudian setelah itu membawa anaknya pergi ke pasar dan disana sang ibu mengenalkan nama sayur, buah, dan makanan lainnya.

\section{Tabel 2 Storyline}

\begin{tabular}{|l|l|}
\hline Scene & Cerita \\
\hline Scene 1 & $\begin{array}{l}\text { Sang ibu akan mengajari } \\
\text { anak mengenal huruf }\end{array}$ \\
\hline Scene 2 & $\begin{array}{l}\text { Sang ibu akan mengajak } \\
\text { anak pergi ke pasar dan } \\
\text { mengenal buah dan sayur } \\
\text { sayuran }\end{array}$ \\
\hline Scene 3 & $\begin{array}{l}\text { Setelah kembali dari pasar } \\
\text { sang ibu akan memberikan } \\
\text { pertanyaan kepada anaknya } \\
\text { dalam mengenali buah } \\
\text { buahan }\end{array}$ \\
\hline
\end{tabular}

\section{Storyboard}

Berdasarkan storyline yang telah ada, maka dibuatlah storyboard dengan gambar kasar untuk menggambarkan adegan dalam game yang akan dimainkan nanti. 


\section{Gambar 8 Storyboard}

\section{Interfaces}

Antarmuka merupakan mekanisme komunikasi antara pengguna dengan sistem. Antarmuka dapat menerima informasi dari pengguna dan memberikan informasi kepada pengguna untuk membantu mengarahkan alur penelusuran masalah sampai ditemukan suatu solusi.

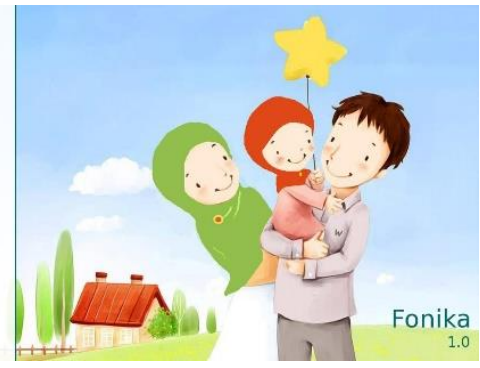

\section{Gambar 9 Interfaces}

Berikut user interfaces yang dibuat dalam game ini:
a. Menu Utama
b. Texs Box
c. Ibu
d. Percakapan
e. Menu Pilihan
f. Percakapan dan Konten Gambar

\section{Pengumpulan Materi}

File gambar yang telah dibuat berupa jpg dan png kemudian disatukan kedalam project agar bisa digunakan. Untuk memasukkan gambar kedalam project, bisa membuka folder renpy kemudian membuka folder game berdasarkan nama project yang telah dibuat. Setelah itu bukalah folder game dan cari folder image, kemudian pindahkan file tersebut kedalam folder tersebut.

Untuk file audio yang telah direkam, akan dipindahkan melalui handphone, karena proses perekaman suara dilakukan melalui handphone. Peletakan file audio pada game ini bisa dengan membuka file renpy, kemudian membuka folder game dan kopikan file audio yang ada kedalam folder tersebut.

\section{Penyusunan dan Pembuatan}

Pada tahap ini proses pembuatan aplikasi sesuai dengan diagram alir melalui flowchart ataupun storyboard yang dibuat sebelumnya, bahasa pemograman untuk pembuatan Aplikasi yaitu menggunakan action script 2.0 pada Adobe Flash CS 6.

Waktunya proyek multimedia diproduksi. Materi-materi serta file-file multimedia yang sudah didapat kemudian dirangkai dan disusun sesuai desain.

Dalam penyusunan ini akan digunakan file sebagai berikut:

1. Script.Rpy

2. Gui.Rpy

3. Options.Rpy

4. Screens.Rpy

\section{Pengujian}

Tahap testing yaitu dilakukan setelah tahap pembuatan dengan menjalankan aplikasi dan melihatnya apakah ada kesalahan atau tidak, kemudian dilakukan pengujian blackbox dalam menguji beberapa fungsi yang salah atau hilang, desain interface, kesalahan performa atau lainnya.

Setelah hasil dari proyek multimedia jadi, perlu dilakukan uji coba. Uji coba dilakukan dengan menerapkan hasil dari proyek multimedia tersebut pada pembelajaran. Hal ini dimaksudkan agar apa yang telah dibuat sebelumnya memang tepat sebelum dapat diterapkan dalam pembelajaran secara massal. Pada penelitian ini akan menggunakan metode Black Box.

Tabel 3 Pengujian Black Box

\begin{tabular}{|l|l|l|l|}
\hline No & Pengujian & $\begin{array}{l}\text { Hasil yang } \\
\text { Diharapkan }\end{array}$ & $\begin{array}{l}\text { Kesimpu } \\
\text { lan }\end{array}$ \\
\hline 1 & $\begin{array}{l}\text { Memulai } \\
\text { game }\end{array}$ & $\begin{array}{l}\text { Game } \\
\text { terbuka }\end{array}$ & $\begin{array}{l}\text { [ v ] } \\
\text { Sukses } \\
{[\text { ] }}\end{array}$ \\
\hline
\end{tabular}


Volume 9 No.2 | Agustus 2019: 358-368

\begin{tabular}{|c|c|c|c|}
\hline & & & Gagal \\
\hline 2 & $\begin{array}{l}\text { Tombol } \\
\text { Start }\end{array}$ & $\begin{array}{l}\text { Memulai } \\
\text { Game }\end{array}$ & $\begin{array}{l}{[\mathrm{v}]} \\
\text { Sukses } \\
{\left[\begin{array}{l}\quad \\
\text { Gagal }\end{array}\right.}\end{array}$ \\
\hline 3 & $\begin{array}{l}\text { Tombol } \\
\text { About }\end{array}$ & $\begin{array}{l}\text { Menampilk } \\
\text { an Menu } \\
\text { about }\end{array}$ & $\begin{array}{l}{\left[\begin{array}{ll}\mathrm{v} & ] \\
\text { Sukses }\end{array}\right.} \\
{\left[\begin{array}{c}\quad \\
\text { Gagal }\end{array}\right.}\end{array}$ \\
\hline 4 & $\begin{array}{l}\text { Klik pada } \\
\text { layar } \\
\text { untuk } \\
\text { melanjutk } \\
\text { an dialog }\end{array}$ & $\begin{array}{l}\text { Ketika } \\
\text { diklik akan } \\
\text { melanjutka } \\
\text { n ke dialog } \\
\text { berikutnya }\end{array}$ & $\begin{array}{l}{\left[\begin{array}{ll}\mathrm{v} & ] \\
\text { Sukses }\end{array}\right.} \\
{\left[\begin{array}{c}\quad \\
\text { Gagal }\end{array}\right.}\end{array}$ \\
\hline 5 & $\begin{array}{l}\text { Memilih } \\
\text { menu } \\
\text { pilihan }\end{array}$ & $\begin{array}{l}\text { Berhasil } \\
\text { membuat } \\
\text { pilihan }\end{array}$ & $\begin{array}{l}{[\mathrm{v}]} \\
\text { Sukses } \\
{[\quad]} \\
\text { Gagal }\end{array}$ \\
\hline 6 & $\begin{array}{l}\text { Memilih } \\
\text { konten } \\
\text { gambar }\end{array}$ & $\begin{array}{l}\text { Berhasil } \\
\text { embuat } \\
\text { pilihan }\end{array}$ & $\begin{array}{l}\text { [ v }] \\
\text { Sukses } \\
{\left[\begin{array}{l}\quad \\
\text { Gagal }\end{array}\right.}\end{array}$ \\
\hline
\end{tabular}

Setelah melakukan pengujian black box, maka akan dilakukan pengujian kelayakan, berikut adalah tabel kuesioner untuk pengujian kelayakan.

Tabel 4 Pengujian Kelayakan

\begin{tabular}{|l|l|l|l|l|l|l|}
\hline No & Pernyataan & \multicolumn{4}{|c|}{ Keterangan } \\
\cline { 3 - 6 } & SS & S & KS & TS & STS \\
\hline 1 & $\begin{array}{l}\text { Apakah } \\
\text { menu dalam } \\
\text { game yang } \\
\text { telah dibuat }\end{array}$ & & & & & \\
\hline
\end{tabular}

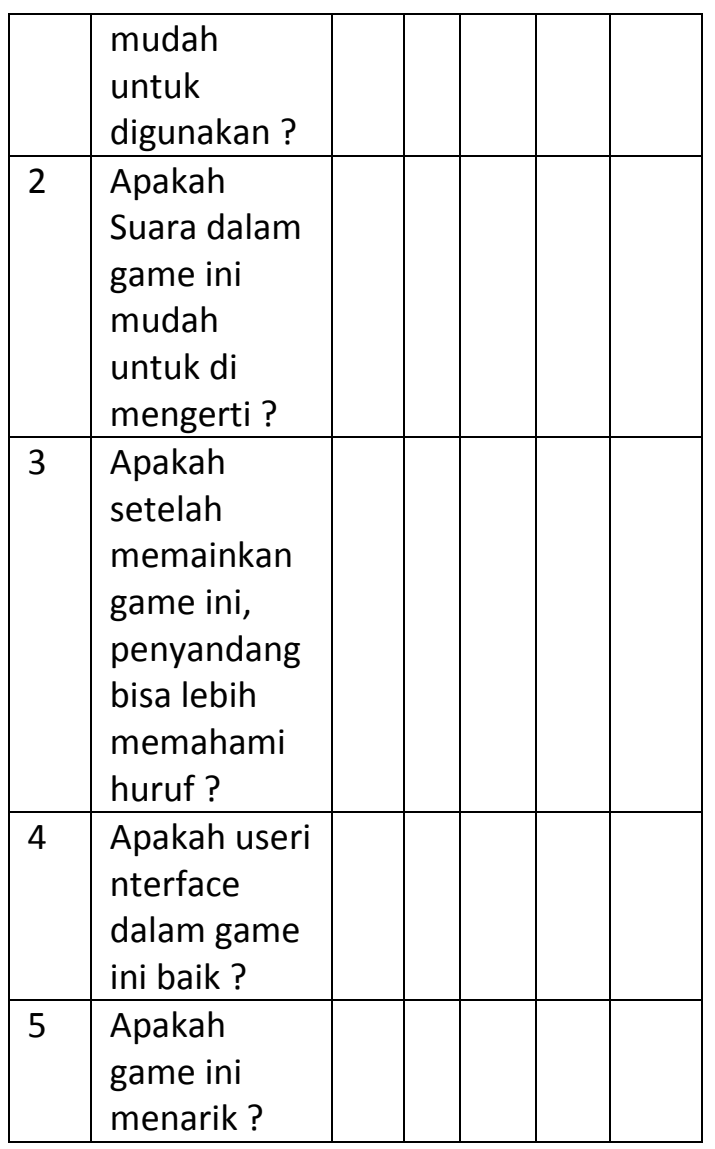

Kuesioner diatas dilakukan oleh 5 orang anak disleksia, setelah dilakukan perhitungan, maka didapat lah bahwa $79,02 \%$ dari 5 anak itu setuju jika jika game ini bisamembuat mereka lebih paham.

\section{Penyebarluasan}

Pada tahap ini aplikasi yang selesai dibuat akan disimpan dalam bentuk file *.apk, tahap ini belum bisa menjadi tahap akhir apabila masih terdapat pengembangan produk untuk menjadi lebih baik lagi. Dan sekaligus menjadi evaluasi untuk pengembangan produk dikemudian hari. Penyebarluasan akan dilakukan melalui blogger.

\section{PENUTUP}

Setelah dilakukan penelitian maka didapatkanlah sebuah kesimpulan dan saran pada game ini. 


\section{Kesimpulan}

Game visual novel ini merupakan suatu media pembelajaran yang menggunakan sebuat metode penyampaian berupa metode fonik yang menekankan pembelajaran pada aspek audio. Berikut kesimpulan yang didapat dari proses pengujian blackbox dan pengujian kelayakan :

1. Berdasarkan pengujian blackbox yang telah dilakukan, pada game ini, maka didapatkan hasil bahwa fungsi-fungsi pada game ini bisa berjalan dengan baik, tanpa ada gangguan.

2. Berdasarkan pengujian kelayakan yang telah dilakukan kepada 5 anak penyandang disleksia, didapatkan hasil keseluruhan sebesar 79,2\% termasuk dalam kategori layak.

\section{Saran}

Berdasarkan kesimpulan tersebut, ada beberapa saran yang dapat disampaikan yaitu, dalam game ini ada beberapa aspek seperti audio dan user interface masih memiliki kekurangan, jadi game ini bisa lebih dikembangkan dalam 2 aspek tersebut.

\section{DAFTAR PUSTAKA}

Adrie Satrio, A. G. (2017). Pengembangan Visual Novel Game Mata Pelajaran Ilmu Pengetahuan Sosial Di Sekolah Menengah Pertama . Yogyakarta: Pascasarjana Universitas Negeri Yogyakarta .

Ardyanti, W. (2015). Penggunaan Metode Fonik Untuk Meningkatkan Kemampuan Membaca Permulaan Pada Anak Berkesulitan Belajar Kelas 2 di SD N Jagamansan 1. Yogyakarta: Universitas Negeri Yogyakarta.
Arifah, H. N. (2017). Pengembangan Multimedia Pembelajaran Interaktif Untuk Keterampilan Membaca Permulaan Siswa Berkesulitan Membaca (Disleksia) Kelas III Di SD Negeri Bangunrejo II Kricak Tegalrejo. Yogyakarta: Universitas Negri Yogyakarta.

Azizah, I. N. (2016). Pembuatan Game "Two Dis" Untuk Terapi Membaca Bagi Anak Disleksia Dan Diskalkulia Berbasis Android. Surakarta: Universitas Sebelas Maret.

Braghirolli, L. F., Duarte Ribeiro, J. L., \& Weise, A. D. (2016). Benefits of educational games as an introductory activity in industrial engineering education. Computers In Human Behavior, 315-324.

Dewi, K. (2015). Disleksia.

Lestari, d. (2015). Dysfun Course (Kursus membaca dan menulis pertama di Indonesia bagi anak-anak yang mengidap Disleksia).

Lestari, D. (2015). Penanganan Anak Hiperaktif Melalui Terapi Permainan Puzzle Di Kelompok Kb Paud Saymara Kartasura.

Madinatul Munawaroh, N. T. (2015). Mengenali Tanda-Tanda Disleksia Pada Anak Usia Dini. 168.

Molina, D. N. (2014). Rancang Bangun Edugame untuk Pembelajaran Profil Negara-Negara ASEAN Berbasis Android.

Muhaeminah. (2015). Game Therapy Untuk Meningkatkan Sense Of Belonging Anak Panti Asuhan. 
Patricia, J. W. (2016). Perancangan Board Game sebagai Media Terapi Penyakit Demensia Ringan pada Lansia.

Prasetyowati, C. W. (2014). Pengaruh Game Digital Terhadap Metode Intervensi Anak Disleksia.

Purnomo, d. (2017). Pengembangan Game Untuk Terapi Membaca Bagi Anak Disleksia Dan Diskalkulia.

Ramadhani, H. S. (2016). Pengaruh Terapi Bermain Puzzle Terhadap Konsentrasi Belajar Anak Kelas 1 Di Sd Negeri Pokok 1 Ngemplak, Sleman, D.I. Yogyakarta.

Safaat, N. (2015). Android : Pemograman Aplikasi Mobile Smartphone dan Tablet PC Berbasis Android.

Sri Respati Andamari, S. R. (2017). Implementasi Terapi Berbasis Aplikasi Android dan Terapi Verbal untuk Meningkatkan Kemampuan Membaca pada Anak dengan Gejala Disleksia. Jurnal Psikologi, 21.

Sudarmilah, E. d. (2015). Popular Games, Can Any Concept of Cognitive Prescholers Be In It?

Tammasse, J. T. (2017). Mengatasi Kesulitan Belajar Disleksia. Studi Neuropsikolinguistik, 11.

Virdyna, N. K. (2015). Penerapan Metode Fonik Dalam Pembelajaran Bahasa Inggris Bagi Anak Usia Dini. Jurnal Bahasa Inggris, Vol. 1, Tahun X, Hal. 119. 